\title{
A VENDOR-BUYER OPTIMAL CONSIGNMENT POLICY FOR A SEASONAL PRODUCT WITH UNIFORM DISTRIBUTION OF DEMAND
}

\author{
S. M. S. Islam* and M. A. Hoque \\ Mathematical and Computing Sciences Group, University Brunei Darussalam, Brunei \\ ${ }^{*}$ Corresponding Author: sislam.math@gmail.com
}

\begin{abstract}
Use of seasonal products is common in our life. Control of management cost of these products plays an important role in delivering them to customers with reasonable prices and profit. Some research has been carried out with uniform distribution of demands to maximize profit independently for the vendor and the buyer, and also for the integrated system by considering shortage cost and inventory cost of the unsold items. In the latter system the vendor is liable for shipment, and bears financial holding cost by keeping items in the buyer's warehouse but retains the ownership, and the buyer bears only the operational holding cost. To make a fruitful consignment agreement, the vendor guarantees the buyer to earn at least as much as in traditional policy by offering the buyer an extra incentive along with the agreed commission. However, warehouse capacity, transport cost and inventory cost during processing of a product and meeting demand are essential in this system. To make the available models more realistic, this study extends them including these factors. New solution techniques to the extended models are developed, and the effects of the included factors are highlighted by comparative studies on the results of numerical problems.
\end{abstract}

(Keywords: Consignment policy; Traditional policy; Newsboy problem; Inventory; Transport)

\section{INTRODUCTION}

Seasonal products (products that are only marketed in some particular times of the year, for examples, holyday greeting cards, winter accessories, fresh fruits, etc.) are very essential in our common life. Nowadays, arrangement of various sporting and cultural events is influencing to make new dimensional seasonal products (such as world cup match tickets, stickers relating important events, some special T-shirt etc.) with its new market demand. A suitable seasonal marketing policy is very essential for successful management of seasonal products to make them available to the consumers with reasonable price and required amount. Generally, the demand of seasonal products is zero before or after the season, and it does not go to infinity over the entire season but fluctuates in a range. This property mostly matches with the property of uniform distribution. So, in this paper, we present a single vendor single buyer profit maximizing model with uniform distribution of demand for a seasonal product and we also compare two marketing policies for identifying the better one. Quick review of some research papers for traditional policy (TP) and consignment policy (CP) states the following assumptions which have been considered in this paper.

In the TP, the buyer (retailer) buys the products from the vendor (manufacturer) by paying wholesale price and then carries them into its warehouse for selling them to the consumers with the retail price. The buyer sets its order quantity to maximize the expected profit and the vendor independently fixes the wholesale price of the product to maximize its own expected profit. On the other hand, under a CP agreement, the vendor is liable for transshipment, and bears financial holding cost by keeping items in the buyer's warehouse but retains the ownership. The vendor offers the buyer sales commission on each sold item and a fixed fee to guarantee the buyer to earn at least as much as in TP. Whereas, the buyer bears the operational holding cost of goods and deducts the agreed commission from the selling price of each sold item and remits the balance to the vendor. There is no exchange of money between the buyer and the vendor until an item is sold. The vendor wants to maximize its expected profit as well as the total supply-chain expected profit based upon the buyer's order quantity and fixes the sales commission of each sold items in such a way that the buyer's order quantity also maximizes the entire supply-chain expected profit. They both are motivated together to sell more products by sharing information.

Though, consignment policy is a new approach to supply-chain inventory management, it has widely been adopted by some world famous retailers (e.g., Dillard Department Stores, Wal-Mart, Amazon.com, etc.) of various countries very shortly $([1,2,3])$ as it is more beneficial. The buyer can decrease its inventory costs by $50 \%$ under CP because it bears a part (operational part) of inventory cost and the other part (financial part) of inventory cost is carried by the vendor [4]. [5] indicated that the per-unit inventory holding cost comprises two main components: operational and financial. The operational one is the pure storage material handling costs, insurance costs 
and so on. On the other hand, the financial one regards the costs of producing goods, such as capital and taxes. The amounts of both holding costs are approximately identical, but sometimes the financial one is greater than the operational one. It was shown in [6] that the total inventory cost of a product is about one-third of its production cost. In the initial stage of $\mathrm{CP}$, they also established a profit maximizing model, based on the single-period newsboy problem and make-to-order production approach (vendor starts production getting sales order from the buyer), considering only the holding cost of unsold products and a good-will loss due to shortage. In our study, their model is basic one and we are concern about the demand pattern of seasonal products, production time inventory, shipping time inventory, selling period average inventory, transshipment cost and highest capacity of buyer's warehouse including the factors considered by them. A comparison of our model with their one is shown numerically.

Unfortunately, most prior research focuses on models to minimize the cost of inventory in lieu of profit maximization. In [7], a joint economic lot size model is proposed, that minimized the total cost of the supply chain. Voros [8] analyzed the effect of risk incurring at companies producing highly seasonal products using uniform distribution of demand. But Panda et al. [9] presented a model for seasonal products considering ramp-type time dependent demand. In their paper, demand gradually decreases after some time but it exists when time tends to infinity, which does not go with the concept of seasonal product. The uniform distribution demand is best fit for new product inventory management by [10]. From [11], make-to-order production approach and internal information sharing between both parties can increase the supply chain profit by reducing the inventory holding cost. It has been proved that the implication of CP is better than the implication of TP for both the vendor and the buyer by many researchers such as $[12,13,14]$. A lot of researchers have considered selling period average inventory of sold products and shipping time inventory with other factors in their studies (e.g., [9, 15, 16, 17]. This literature review inspires us to do the present study which is more realistic and significant in business arena.

We organize the paper as follows: In section 2, we develop the models under TP and CP with uniform distribution of demand and find out its optimal solutions. Section 3 presents a solution algorithm. Numerical illustrations and retail price markdown are shown in section 4 and section 5 respectively. Finally, section 6 concludes by highlighting the paper findings, managerial implications, limitations and future research directions.

\section{MODEL FORMULATION}

In this paper, we attempt to formulate a profit maximization model under $\mathrm{CP}$ within a vendor and a buyer of one product with stochastic demand, $x$ to be uniform distribution with probability density function $f(x) \quad$ (i.e., $\quad x \sim \mathrm{u}[\mu-\sigma / 2, \quad \mu+\sigma / 2]$, where $\mathrm{u}$ represents uniform distribution, $\sigma$ is the consumer demand variability, $\mu$ denotes mean demand and $f(x)=1 / \sigma$ is the uniform probability density function). The single-period newsboy approach has been used in the proposed model and it is compared with the similar one under TP. The mathematical model in this paper is developed using following notations.

Notation:

$P \quad$ Retail price per unit

$w \quad$ Wholesale price per unit paid by the buyer to the vendor in TP

c Manufacturing cost per unit occurred at vendor's side

$\alpha$ Sales commission paid by the vendor to the buyer on each sold item

$A$ Incentive (fixed) fee paid by the vendor to the buyer

$\mu \quad$ Expected value of consumer demand

$\sigma$ Length of the initial consumer demand distribution

$x \quad$ Priors knowledge about history of consumer demand; $x \sim \mathrm{u}[\mu-\sigma / 2, \mu+\sigma / 2]$

$Q \quad$ Order quantity

$s_{b} \quad$ Goodwill loss due to per-unit lost-sale faced by the buyer

$s_{v} \quad$ Goodwill loss due to per-unit lost-sale faced by the vendor

$s_{t} \quad$ Total goodwill loss for per unit lost-sale; $s_{t}=$ $s_{b}+s_{v}$

$T \quad$ Cycle time or buyer's selling period

$t$ Time taken for the shipment (a fraction of cycle time, $T$ )

$c_{t} \quad$ Per-unit transshipment cost

$p_{v} \quad$ Production rate per cycle

$g \quad$ Highest capacity of the buyer's warehouse, so, $Q \leq g$

$h_{b}^{C P} \quad$ Per-unit holding (operational part) cost carried by the buyer per cycle in $\mathrm{CP}$

$h_{v}^{C P}$ Per-unit holding (financial part) cost carried by the vendor per cycle in $\mathrm{CP}$

$h_{t}^{C P} \quad$ Total of per-unit per-cycle holding cost in CP; $h_{t}^{C P}=h_{b}^{C P}+h_{v}^{C P}$ 
$h_{b}^{T P} \quad$ Per-unit holding cost incurred to the buyer per cycle in TP

$h_{v}^{T P} \quad$ Per-unit holding cost incurred to the vendor per cycle in TP

$\pi_{b}^{K}$ The buyer's profit per cycle under CP or TP, where $K \in\{\mathrm{CP}, \mathrm{TP}\}$

$\pi_{v}^{K} \quad$ The vendor's profit per cycle under CP or TP, where $K \in\{\mathrm{CP}, \mathrm{TP}\}$

$\pi_{t}^{C P}$ Supply-chain profit per cycle under CP

Since the probability of demand outside the range $[\mu-\sigma / 2, \mu+\sigma / 2]$ is zero, the order quantity $Q$ should not be greater than $\mu+\sigma / 2$. If a buyer unwisely orders more than $\mu+\sigma / 2$ then the extra quantities ordered by the buyer obviously will add some extra (production, holding, transshipment, etc.) cost in the supply-chain without giving any benefit because this extra amount has no participation in the selling business. So, $1 \leq Q \leq \mu+\sigma / 2$ is an realistic assumption in the paper. Another assumption is that the vendor has sufficient production ability to meet up the buyer's order.

From the figure 1, production time inventory $=Q^{2} / 2$ $p_{v}$, shipping time inventory $=Q t$ and inventory in buyer's warehouse $=$ selling period inventory of sold products + inventory of unsold products $=x / 2+(Q-$ $x)=(Q-x / 2)$ when $x \leq Q$ otherwise $Q^{2} / 2 x$. And the shortage amount is $x-Q$ when $x>Q$.

Based on the above notations, assumptions, calculated inventories and shortage, we develop our model under CP. To make a comparison, firstly, we present a similar model under TP.

\section{Traditional policy}

Under TP, based on the above discussion and notations, the buyer's profit function becomes:
$\pi_{b}^{T P}= \begin{cases}p x-w Q-h_{b}^{T P}\left(Q-\frac{1}{2} x\right)-Q c_{t}-Q t h_{b}^{T P} & ; \quad x \leq Q \\ p Q-w Q-\frac{Q^{2}}{2 x} h_{b}^{T P}-s_{b}(x-Q)-Q c_{t}-Q t h_{b}^{T P} ; & x>Q\end{cases}$

So, the buyer's expected profit is

$$
\begin{aligned}
E\left(\pi_{b}^{T P}\right)= & \int_{0}^{Q}\left[p x-h_{b}^{T P}\left(Q-\frac{1}{2} x\right)\right] f(x) d x+\int_{Q}^{\infty}\left[p Q-\frac{Q^{2}}{2 x} h_{b}^{T P}-s_{b}(x-Q)\right] f(x) d x \\
& -w Q-c_{t} Q-t h_{b}^{T P} Q, \\
E\left(\pi_{b}^{T P}\right)= & \mu\left(p+\frac{1}{2} h_{b}^{T P}\right)-Q\left(w+c_{t}+h_{b}^{T P}+t h_{b}^{T P}\right)-\frac{1}{2 \sigma}\left(p+s_{b}+\frac{1}{2} h_{b}^{T P}\right)\left(Q-\mu-\frac{\sigma}{2}\right)^{2} \\
& -\frac{1}{2 \sigma} Q h_{b}^{T P}\left(Q-\mu-\frac{\sigma}{2}\right)-\frac{1}{2 \sigma} Q^{2} h_{b}^{T P}\left\{\ln \left(\mu+\frac{\sigma}{2}\right)-\ln Q\right\}
\end{aligned}
$$

(See equation (A1) in appendix)

The vendor's expected profit is

$$
E\left(\pi_{v}^{T P}\right)=(w-c) Q-\frac{Q^{2}}{2 p_{v}} h_{v}^{T P}
$$

Warehouse capacity constra int: $Q \leq g$

Since, $E\left(\pi_{b}^{T P}\right)$ is concave in $Q$ (the proof is shown by eqn. (A3) in appendix), $d E\left(\pi_{b}^{T P}\right) / d Q=0$ from equation (2) gives the optimal order quantity, $Q$, for buyer's expected profit in the implicit form as follows (calculations are shown in eqn. (A2) in appendix):

$$
\begin{aligned}
Q\left\{h_{b}^{T P} \ln Q-h_{b}^{T P}\right. & \left.\ln \left(\mu+\frac{\sigma}{2}\right)-p-s_{b}-h_{b}^{T P}\right\}-\sigma\left(w+c_{t}+h_{b}^{T P}\right. \\
+ & \left.t h_{b}^{T P}\right)+\left(p+s_{b}+h_{b}^{T P}\right)\left(\mu+\frac{\sigma}{2}\right)=0
\end{aligned}
$$

Equation (5) shows that $Q$ is a function of $w$. As $E\left(\pi_{v}^{T P}\right)$ in equation (3) is concave for w (the proof is presented by eqn. (A7) in appendix), so, $d E\left(\pi_{v}^{T P}\right) / d w=0$ from equation (3) gives the optimal wholesale price, w in terms of $Q$ (the proof is shown by eqn. (A6) in appendix).
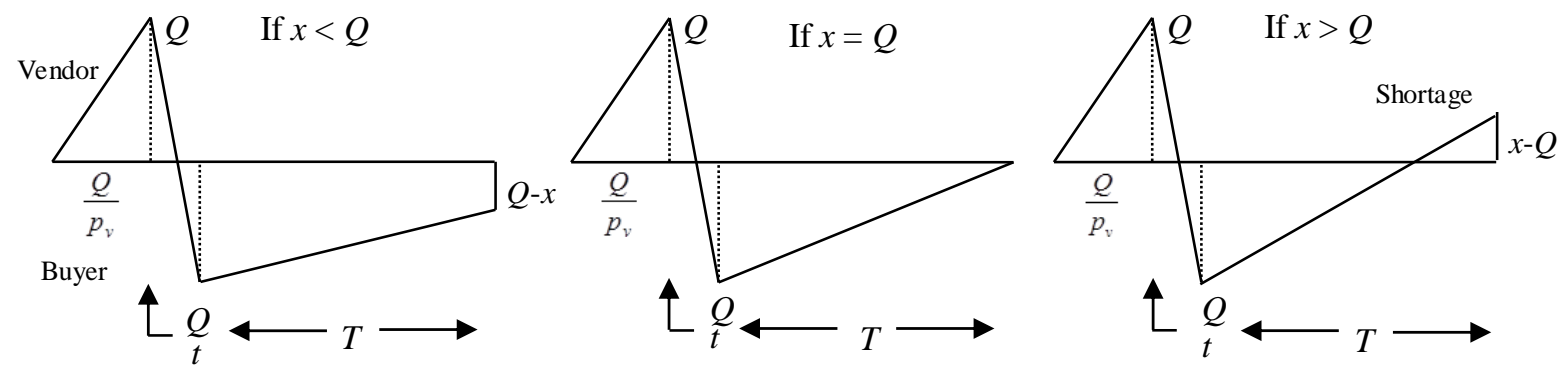

Figure 1. The inventories of the vendor and the buyer in all the three situations 
$w^{*}=c+\frac{Q}{p_{v}} h_{v}^{T P}-\frac{Q\left[h_{b}^{T P}\left\{\ln Q-\ln \left(\mu+\frac{\sigma}{2}\right)\right\}-p-s_{b}\right]}{\sigma}(6)$

Elimination of $w$ from equation (5) gives equation (7) to find the value of $Q$

$$
\begin{aligned}
& 2 Q h_{b}^{T P} \ln Q-Q\left\{2 h_{b}^{T P} \ln \left(\mu+\frac{\sigma}{2}\right)+h_{b}^{T P}+\frac{\sigma}{p_{v}} h_{v}^{T P}+2 p+2 s_{b}\right\} \\
& +\left(p+s_{b}+h_{b}^{T P}\right)\left(\mu+\frac{\sigma}{2}\right)-\sigma\left(c+c_{t}+h_{b}^{T P}+t h_{b}^{T P}\right)=0
\end{aligned}
$$

The realistic assumptions and the capacity constraint (4) together show that the optimal order quantity $Q$ comes from the following formula:

$Q^{*}=\min$. of $\{\mu+\sigma / 2, g, Q$ calculated fromeqn.(7) $\}$

If the optimal order quantity calculated from equation (8) is less than the order quantity calculated from equation (7) then by increasing the value of $w$, the vendor can increase its profit making the buyer a loser one and even the buyer gets negative profit which is contradictory to real business. So, $w^{*}$ being calculated from equation (6) by using $Q$, calculated from equation (7) will be unchanged. Using $Q^{*}$ and $w^{*}$, the optimal expected profits of the buyer and the vender are calculated from equations (2) and (3) respectively. The total supply-chain expected profit is $E\left(\pi_{b}^{T P}\right)+E\left(\pi_{v}^{T P}\right)$.

\section{Consignment policy}

The profits of the buyer, the vendor and the entire supply-chain are in equation (9), (10) and (11) respectively.

$$
\pi_{b}^{C P}= \begin{cases}\alpha x-h_{b}^{C P}\left(Q-\frac{1}{2} x\right)+A & ; \quad x \leq Q \\ \alpha Q-\frac{Q^{2}}{2 x} h_{b}^{C P}-s_{b}(x-Q)+A ; & x>Q\end{cases}
$$

$$
\pi_{v}^{C P}=\left\{\begin{array}{c}
(p-\alpha) x-c Q-h_{v}^{C P}\left(Q-\frac{1}{2} x\right)-Q c_{t}-Q t h_{t}^{C P} \\
-\frac{Q^{2}}{2 p_{v}} h_{t}^{C P}-A \quad ; x \leq Q \\
(p-\alpha-c) Q-\frac{Q^{2}}{2 x} h_{v}^{C P}-s_{v}(x-Q)-Q c_{t} \\
-Q t h_{t}^{C P}-\frac{Q^{2}}{2 p_{v}} h_{t}^{C P}-A ; \quad x>Q
\end{array}\right.
$$

$$
\pi_{t}^{C P}=\left\{\begin{array}{c}
p x-c Q-h_{t}^{C P}\left(Q-\frac{1}{2} x\right)-Q c_{t} \\
-Q t h_{t}^{C P}-\frac{Q^{2}}{2 p_{v}} h_{t}^{C P} ; x \leq Q \\
(p-c) Q-\frac{Q^{2}}{2 x} h_{t}^{C P}-s_{t}(x-Q)-Q c_{t} \\
-Q t h_{t}^{C P}-\frac{Q^{2}}{2 p_{v}} h_{t}^{C P} ; x>Q
\end{array}\right.
$$

Warehousecapacity constraint: $Q \leq g$

So, the expected profits of the buyer, the vendor and the entire supply-chain are given by equation (13), (14) and (15) respectively (calculation process is similar as in equation (2)).

$$
\begin{gathered}
E\left(\pi_{b}^{C P}\right)=A-Q h_{b}^{C P}+\mu\left(\alpha+\frac{1}{2} h_{b}^{C P}\right)+\frac{Q}{2 \sigma} h_{b}^{C P}\left(\mu+\frac{\sigma}{2}-Q\right)-\frac{1}{2 \sigma}(\alpha \\
\left.+s_{b}+\frac{1}{2} h_{b}^{C P}\right)\left(Q-\mu-\frac{\sigma}{2}\right)^{2}-\frac{Q^{2}}{2 \sigma} h_{b}^{C P}\left\{\ln \left(\mu+\frac{\sigma}{2}\right)-\ln Q\right\} \\
E\left(\pi_{v}^{C P}\right)=\mu\left(p-\alpha+\frac{1}{2} h_{v}^{C P}\right)-Q\left(c+c_{t}+h_{v}^{C P}+t h_{t}^{C P}+\frac{Q}{2 p_{v}} h_{t}^{C P}\right) \\
+\frac{Q}{2 \sigma} h_{v}^{C P}\left(\mu+\frac{\sigma}{2}-Q\right)-\frac{1}{2 \sigma}\left(p-\alpha+s_{v}+\frac{1}{2} h_{v}^{C P}\right)\left(Q-\mu-\frac{\sigma}{2}\right)^{2} \\
-\frac{Q^{2}}{2 \sigma} h_{v}^{C P}\left\{\ln \left(\mu+\frac{\sigma}{2}\right)-\ln Q\right\}-A \\
E\left(\pi_{t}^{C P}\right)=\mu\left(p+\frac{1}{2} h_{t}^{C P}\right)-Q\left(c+c_{t}+h_{t}^{C P}+t h_{t}^{C P}+\frac{Q}{2 p_{v}} h_{t}^{C P}\right) \\
+\frac{Q}{2 \sigma} h_{t}^{C P}\left(\mu+\frac{\sigma}{2}-Q\right)-\frac{1}{2 \sigma}\left(p+s_{t}+\frac{1}{2} h_{t}^{C P}\right)\left(Q-\mu-\frac{\sigma}{2}\right)^{2} \\
-\frac{Q^{2}}{2 \sigma} h_{t}^{C P}\left\{\ln \left(\mu+\frac{\sigma}{2}\right)-\ln Q\right\} \quad(15)
\end{gathered}
$$

Equation (15), considering $d E\left(\pi_{t}^{C P}\right) / d Q=0$, gives the optimal value of supply-chain order quantity, $Q$, by the following equation, because $E\left(\pi_{t}^{C P}\right)$ is concave in $Q$.

$$
\begin{gathered}
\frac{Q}{\sigma} h_{t}^{C P} \ln Q-Q\left[\frac{1}{p_{v}} h_{t}^{C P}+\frac{1}{\sigma}\left\{h_{t}^{C P} \ln \left(\mu+\frac{\sigma}{2}\right)+h_{t}^{C P}+p+s_{t}\right\}\right] \\
+\frac{1}{\sigma}\left(p+s_{t}+h_{t}^{C P}\right)\left(\mu+\frac{\sigma}{2}\right)-\left(c+c_{t}+h_{t}^{C P}+t h_{t}^{C P}\right)=0
\end{gathered}
$$

Equation (13), considering $d E\left(\pi_{b}^{C P}\right) / d Q=0$, gives the optimal value of buyer's order quantity, $Q$, by the following implicit equation, because $E\left(\pi_{b}^{C P}\right)$ is concave in $Q$. 


$$
\begin{array}{r}
\frac{Q}{\sigma} h_{b}^{C P} \ln Q-\frac{Q}{\sigma}\left\{h_{b}^{C P} \ln \left(\mu+\frac{\sigma}{2}\right)+h_{b}^{C P}+\alpha+s_{b}\right\} \\
+\frac{1}{\sigma}\left(\alpha+s_{b}+h_{b}^{C P}\right)\left(\mu+\frac{\sigma}{2}\right)-h_{b}^{C P}=0
\end{array}
$$

The vendor wants to maximize the entire supplychain profit. So, the vendor offers sales commission to the buyer so that the order quantity of the buyer (calculated by implicit equation (17)) becomes equal to the order quantity (calculated by equation (16)) of the entire supply-chain. Therefore, putting the value of order quantity calculated from equation (16) in equation (17), we have the following equation for determining the optimal sales commission for per unit, $\alpha^{*}$.

$$
\begin{array}{r}
\frac{\alpha}{\sigma}\left(\mu+\frac{\sigma}{2}\right)-\frac{\alpha Q}{\sigma}=h_{b}^{C P}+\frac{Q}{\sigma}\left\{h_{b}^{C P} \ln \left(\mu+\frac{\sigma}{2}\right)+h_{b}^{C P}+s_{b}\right\} \\
-\frac{Q}{\sigma} h_{b}^{C P} \ln Q-\frac{1}{\sigma}\left(s_{b}+h_{b}^{C P}\right)\left(\mu+\frac{\sigma}{2}\right), \\
\alpha^{*}=\frac{\sigma h_{b}^{C P}+Q\left\{h_{b}^{C P} \ln \left(\mu+\frac{\sigma}{2}\right)+h_{b}^{C P}+s_{b}\right\}-Q h_{b}^{C P} \ln Q-\left(s_{b}+h_{b}^{C P}\right)\left(\mu+\frac{\sigma}{2}\right)}{\mu+\frac{\sigma}{2}-Q}
\end{array}
$$

The realistic assumptions and the capacity constraint (12) together show that the actual optimal order quantity $\mathrm{Q}^{*}$ incurred by the entire supply-chain, comes from the following formula:

$Q^{*}=\min$. of $\{\mu+\sigma / 2, g, Q$ calculated from eqn.(16) $\}$

Though the optimal order quantity, $\mathrm{Q}^{*}$ calculated from equation (19) is less than the order quantity calculated from equation (16), there is no chance to increase the vendor's profit by changing the value of $\alpha^{*}$ yet. So, $\alpha^{*}$ being calculated from equation (18) by using $\mathrm{Q}$, calculated from equation (16) will be unchanged.

To form a successful CP, the vendor ensures the buyer to earn at least as much as in TP (i.e., $\left.E\left(\pi_{b}^{C P}\right) \geq E\left(\pi_{b}^{T P}\right)\right)$.

In this regard, the vendor provides the buyer the fixed fee $\mathrm{A}$ at least by equation (20).

$$
\begin{gathered}
A=E\left(\pi_{b}^{T P}\right)-\mu\left(\alpha+\frac{1}{2} h_{b}^{C P}\right)-\frac{Q}{2 \sigma} h_{b}^{C P}\left(\mu+\frac{\sigma}{2}-Q\right)+Q h_{b}^{C P}+ \\
\frac{1}{2 \sigma}\left(\alpha+s_{b}+\frac{1}{2} h_{b}^{C P}\right)\left(Q-\mu-\frac{\sigma}{2}\right)^{2}+\frac{Q^{2}}{2 \sigma} h_{b}^{C P}\left\{\ln \left(\mu+\frac{\sigma}{2}\right)-\ln Q\right\}
\end{gathered}
$$

Equations (13), (14) and (15), by using the values of $Q^{*}, \alpha^{*}$ and $A$, gives the optimal expected profit of the buyer, the vendor and the entire supply-chain respectively.

The solution methodology we have discussed so far can be summarized and structured by the following algorithm.

\section{ALGORITHM}

Step 0: Initialize $p, p_{v}, g, c, c_{t}, s_{b}, s_{v}, s_{t}, t, T$, $h_{b}^{T P}, h_{v}^{T P}, h_{b}^{C P}, h_{v}^{C P}, h_{t}^{C P}, \mu$ and $\sigma$ as given.

Under TP

Step 1: Sequentially determine $Q$ and $w^{*}$ using equations (7) and (6) respectively and then calculate $Q^{*}$ by using equation (8).

Step 2: Using $Q^{*}$ and $w^{*}$ in equations (2) and (3), calculate $E\left(\pi_{b}^{T P}\right)$ and $E\left(\pi_{v}^{T P}\right)$ respectively and calculate the entire supply-chain profit by $E\left(\pi_{b}^{T P}\right)+E\left(\pi_{v}^{T P}\right)$.

Under CP

Step 3: Sequentially determine $Q$ and $\alpha^{*}$ using equations (16) and (18) respectively and then calculate $Q^{*}$ by using equation (19).

Step 4: Using $Q^{*}$ and $\alpha^{*}$, determine least fixed fee $A$ from equation (20) and then calculate the expected optimal profits $E\left(\pi_{b}^{C P}\right), E\left(\pi_{v}^{C P}\right)$ and $E\left(\pi_{t}^{C P}\right)$ from equations (13), (14) and (15) respectively.

\section{NUMERICAL ILLUSTRATIONS}

Referring to the existing literature, we consider two examples where the market demand is considered to satisfy the uniform distribution in the domain $[\mu-$ $\sigma / 2, \mu+\sigma / 2]$. And the parameters $p=\$ 30, c=\$ 10$, $c_{t}=0.05 \mathrm{c}, p_{v}=500, s_{b}=s_{v}=s_{t}=0, g=200, T=$ $0.25 \mathrm{yr}, t=0.03 T, \mu=100$ and $\sigma=200$ are set for both examples. In the first example, total holding cost is $20 \%$ of production cost (i.e., $h_{b}^{T P}=h_{v}^{T P}=$ $0.2 c$ in $\mathrm{TP}$ and $h_{t}^{C P}=0.2 c, h_{b}^{C P}=0.08 c, h_{v}^{C P}=$ $0.12 c$ are considered in $\mathrm{CP}$ ) and in the second one, holding cost is $36 \%$ of production cost (i.e., $h_{b}^{T P}=$ $h_{v}^{T P}=0.36 c$ in TP and $h_{t}^{C P}=0.36 c, h_{b}^{C P}=0.18 c$, $h_{v}^{C P}=0.18 c$ are assumed in CP). 
Various results are shown in Table 1-4 and by Figure 2. The expected profits of all parties in TP and CP, calculated by using our model and Chen-Liu's one (considering partial parameters), are presented in Table 1 and Table 2 respectively. By Table 1-2, profits of all parties and values of all important factors except are higher in Chen-Liu's model. The comparisons of the expected profits calculated by both models are in Table 3. It shows that profit calculated in our model is reduced by $11.87-20.45 \%$ compared to that in Chen-Liu and this is happened because we have considered the cost for obvious operations such as production time inventory, shipping time inventory, selling period average inventory and transshipment. Table 4 shows that the adaptation of CP not only increases the profit of the vendor by $49 \%$, but also improves supply-chain profit by $32.47 \%$. In Figure 2, the retailer's expected profit initially rises with the growth of demand uncertainty up to $=170$ then falls. But the expected profits of the manufacturer and the supply-chain decrease gradually as the demand uncertainty increases.

Table 1. The expected profit of the supply chain in TP

\begin{tabular}{|c|c|c|c|c|c|c|c|c|c|c|}
\hline \multirow[t]{2}{*}{ Example } & \multicolumn{5}{|c|}{ Results in Chen and Liu's model } & \multicolumn{5}{|c|}{ Results in our model } \\
\hline & $Q$ & $w$ & $E\left(\pi_{b}^{T P}\right)$ & $E\left(\pi_{v}^{T P}\right)$ & $\begin{array}{c}\text { Total } \\
\text { profit }\end{array}$ & $Q$ & $w$ & $E\left(\pi_{b}^{T P}\right)$ & $E\left(\pi_{v}^{T P}\right)$ & $\begin{array}{l}\text { Total } \\
\text { profit }\end{array}$ \\
\hline 1 & 62.50 & 20 & 312.50 & 625.00 & 937.50 & 57.35 & 19.55 & 275.40 & 541.02 & 816.42 \\
\hline 2 & 59.52 & 20 & 297.62 & 595.24 & 892.86 & 51.88 & 19.42 & 246.68 & 478.82 & 725.50 \\
\hline
\end{tabular}

Table 2. The expected profit of the supply chain in CP

\begin{tabular}{|c|ccccc|ccccccc|}
\hline \multirow{2}{*}{ Example } & \multicolumn{4}{|c|}{ Results in Chen and Liu's model } & \multicolumn{4}{c|}{ Results in our model } \\
\cline { 2 - 12 } & $\alpha$ & $A$ & $Q$ & $E\left(\pi_{b}^{C P}\right)$ & $E\left(\pi_{v}^{C P}\right)$ & $\begin{array}{c}\text { Total } \\
\text { profit }\end{array}$ & $\alpha$ & $A$ & $Q$ & $E\left(\pi_{b}^{C P}\right)$ & $E\left(\pi_{v}^{C P}\right)$ & $\begin{array}{c}\text { Total } \\
\text { profit }\end{array}$ \\
\hline 1 & 1.33 & 229.17 & 125.00 & 312.50 & 937.50 & 1250.00 & 1.67 & 192.68 & 114.65 & 275.40 & 806.10 & 1081.50 \\
\hline 2 & 2.65 & 140.06 & 119.05 & 297.62 & 892.86 & 1190.48 & 3.21 & 104.40 & 103.69 & 246.68 & 710.29 & 956.97 \\
\hline
\end{tabular}

Table 3. Comparison of our model and Chen-Liu's

\begin{tabular}{|c|c|c|c|c|c|c|}
\hline \multirow[b]{2}{*}{ Ex. } & \multicolumn{3}{|c|}{$\begin{array}{l}\text { Profit reduction by our } \\
\text { model in TP (Percentage) }\end{array}$} & \multicolumn{3}{|c|}{$\begin{array}{l}\text { Profit reduction by our } \\
\text { model in CP (Percentage) }\end{array}$} \\
\hline & $E\left(\pi_{b}^{T P}\right)$ & $E\left(\pi_{v}^{T P}\right)$ & $\begin{array}{l}\text { Total } \\
\text { profit }\end{array}$ & $E\left(\pi_{b}^{C P}\right)$ & $E\left(\pi_{v}^{C P}\right)$ & $\begin{array}{l}\text { Total } \\
\text { profit }\end{array}$ \\
\hline 1 & 11.87 & 13.44 & 12.92 & 11.87 & 14.02 & 13.48 \\
\hline 2 & 17.12 & 19.56 & 18.74 & 17.12 & 20.45 & 19.61 \\
\hline
\end{tabular}

Table 4. Differences between expected profits under TP and CP of example 1

\begin{tabular}{|c|c|c|c|c|}
\hline & $Q$ & $E\left(\pi_{b}\right)$ & $E\left(\pi_{v}\right)$ & $\begin{array}{c}\text { Total } \\
\text { profit }\end{array}$ \\
\hline $\mathrm{TP}$ & 57.35 & 275.40 & 541.02 & 816.42 \\
\hline $\mathrm{CP}$ & 114.65 & 275.40 & 806.10 & 1081.50 \\
\hline $\mathrm{CP}-\mathrm{TP}$ & 57.30 & 0 & 265.08 & 265.08 \\
\hline Increment & $99.91 \%$ & 0 & $49 \%$ & $32.47 \%$ \\
\hline
\end{tabular}




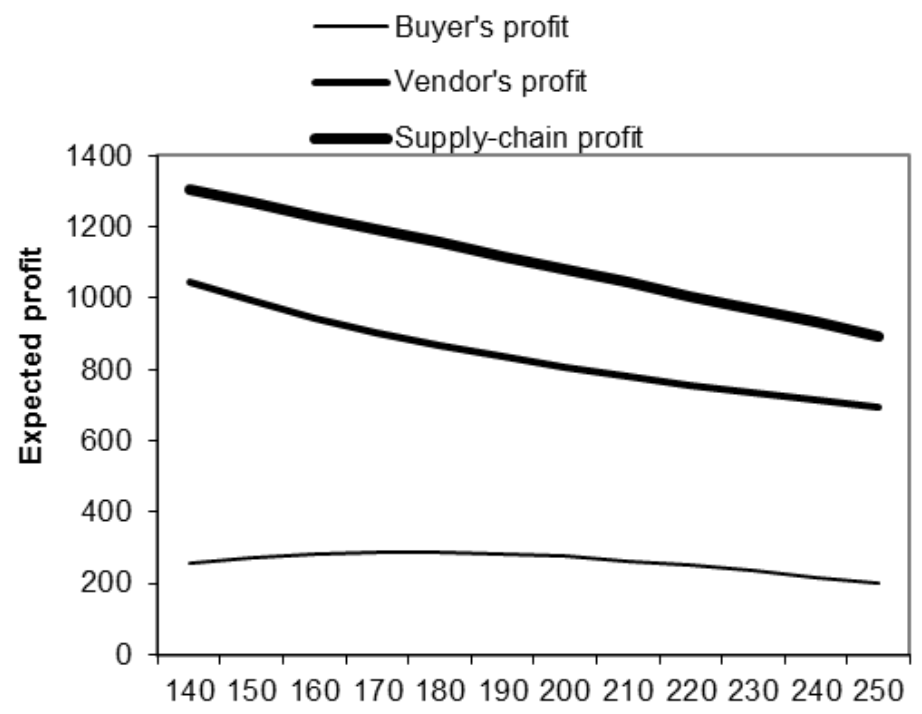

Deviation of demand uncertainty

Figure 2. Expected profit in $\mathrm{CP}$ on demand uncertainty of example 1

\section{Retail price markdown}

Retail price markdown is analyzed for the first example of $\mathrm{CP}$ by considering demand random variable $X=y(p) \cdot x$, where $y(p)=a-b p$ (here $a=30$, $p=30, b \in[0.5,1)$ and $\mathrm{x}$ is uniformly distributed over $[0,200])$ in Table 5 and Table 6 as used by [17, $18,19,20]$.
Table 5 shows that the expected profits for the vendor and the supply-chain increase with the retail price breakdown up to 27 , whereas, the buyer's one becomes optimal when the retail price is 24 . If the buyer enriches the warehouse capacity up to required level, then the expected profits of the vendor, the buyer and the entire supply chain are maximized when the retail price is marked down to 24 per unit (similar to $20 \%$ discount) by Table 6 .

Table 5. Price discount analysis of example 1 under CP

\begin{tabular}{|cccccccccccc|}
\hline \multicolumn{1}{|c}{} & \multicolumn{1}{c}{ Price, } & & & & $E\left(\pi_{b}^{C P}\right)$ & $E\left(\pi_{v}^{C P}\right)$ & $\begin{array}{c}\text { Total } \\
\text { profit }\end{array}$ \\
\hline 200 & 1.0 & 0 & 100 & 200 & 30 & 1.67 & 192.70 & 114.65 & 275.43 & 806.08 & 1081.51 \\
\hline 200 & 0.9 & 3 & 300 & 600 & 27 & 1.36 & 453.88 & 200 & 611.30 & 1523.45 & 2134.75 \\
\hline 200 & 0.8 & 6 & 600 & 1200 & 24 & 1.06 & 622.07 & 200 & 772.42 & 1325.85 & 2098.27 \\
\hline 200 & 0.7 & 9 & 900 & 1800 & 21 & 0.81 & 515.00 & 200 & 635.01 & 1057.50 & 1692.51 \\
\hline 200 & 0.6 & 12 & 1200 & 2400 & 18 & 0.59 & 340.06 & 200 & 425.98 & 765.61 & 1191.59 \\
\hline 200 & 0.5 & 15 & 1500 & 3000 & 15 & 0.37 & 155.85 & 200 & 205.66 & 446.23 & 651.89 \\
\hline
\end{tabular}

Table 6. Price discount analysis of example 1 under CP avoiding capacity constraint

\begin{tabular}{|c|c|c|c|c|c|c|c|c|c|c|}
\hline$b$ & $y(p)$ & $\mu$ & $\sigma$ & $\begin{array}{c}\text { Price, } \\
b p\end{array}$ & $\alpha$ & $A$ & $Q$ & $E\left(\pi_{b}^{C P}\right)$ & $E\left(\pi_{v}^{C P}\right)$ & $\begin{array}{l}\text { Total } \\
\text { profit }\end{array}$ \\
\hline 1.0 & 0 & 100 & 200 & 30 & 1.67 & 192.70 & 114.65 & 275.43 & 806.08 & 1081.51 \\
\hline 0.9 & 3 & 300 & 600 & 27 & 1.36 & 436.82 & 300.91 & 611.30 & 1786.74 & 2398.04 \\
\hline 0.8 & 6 & 600 & 1200 & 24 & 1.06 & 877.36 & 495.17 & 1098.80 & 2126.58 & 3225.38 \\
\hline 0.7 & 9 & 900 & 1800 & 21 & 0.81 & 851.20 & 578.76 & 1048.20 & 1879.91 & 2928.11 \\
\hline 0.6 & 12 & 1200 & 2400 & 18 & 0.59 & 592.87 & 548.54 & 728.75 & 1249.12 & 1977.87 \\
\hline 0.5 & 15 & 1500 & 3000 & 15 & 0.37 & 235.14 & 403.48 & 299.68 & 568.92 & 868.60 \\
\hline
\end{tabular}

\section{CONCLUSION}

The consideration of all realistic factors related to vendor-buyer business, represents a more realistic model for single-vendor single-buyer of a seasonal product in the new business world. This study proves that the implementation of CP increases the vendor's profit as well as the total supply-chain profit compared to TP. The numerical analysis in Table 4 shows that the vendor can earn $49 \%$ more in CP than that of TP. So, a vendor can establish a more reliable $\mathrm{CP}$, by sharing the extra profit with the buyer. And in 
this way, the buyer also gets more revenue under the CP than that in TP. For the mentioned examples, Table 3 indicates that compared to Chen and Liu, the profit of each party as well as the profit of entire supply chain is decreased by $11.87-20.45 \%$ due to the adaptation of some realistic factors such as production time inventory, shipping time inventory, selling period average inventory and transshipment cost, which were not considered in their model. That means the profit of each party calculated by Chen and Liu was $11.87-20.45 \%$ higher than the actual one. Retail price markdowns notice to the manager that both parties will be more beneficial if the retail price is reduced to 24 and the buyer's warehouse capacity constraint is omitted.

This study has been done on some assumptions and fixed demand distribution. It may be extended relaxing the assumptions and considering other type of demand patterns for several vendor-buyers.

\section{ACKNOWLEDGMENT}

The authors would like to thank The University of Brunei Darussalam (Grant number UBD/GRS$\mathrm{ADM} / 01$ ) for the financial support in this study.

\section{APPENDIX}

The buyer's expected profit under TP is as follows

$$
\begin{aligned}
& E\left(\pi_{b}^{T P}\right)=\int_{0}^{Q}\left[p x-h_{b}^{T P}\left(Q-\frac{1}{2} x\right)\right] f(x) d x+\int_{Q}^{\infty}\left[p Q-\frac{Q^{2}}{2 x} h_{b}^{T P}-s_{b}(x-Q)\right] f(x) d x \\
& -w Q-c_{t} Q-t h_{b}^{T P} Q, \\
& =-Q h_{b}^{T P} \int_{0}^{Q} f(x) d x+\left(p+\frac{1}{2} h_{b}^{T P}\right) \int_{0}^{Q} x f(x) d x+Q\left(p+s_{b}\right) \int_{Q}^{\infty} f(x) d x \\
& -s_{b} \int_{Q}^{\infty} x f(x) d x-\frac{1}{2} Q^{2} h_{b}^{T P} \int_{Q}^{\infty} \frac{1}{x} f(x) d x-w Q-c_{t} Q-t h_{b}^{T P} Q \\
& =-Q h_{b}^{T P}\left(1-\int_{Q}^{\mu+\frac{\sigma}{2}} \frac{1}{\sigma} d x\right)+\left(p+\frac{1}{2} h_{b}^{T P}\right)\left(\mu-\int_{Q}^{\mu+\frac{\sigma}{2}} \frac{1}{\sigma} x d x\right)+Q\left(p+s_{b}\right)_{Q}^{\mu+\frac{\sigma}{2}} \frac{1}{\sigma} d x \\
& -s_{b} \int_{Q}^{\mu+\frac{\sigma}{2}} \frac{1}{\sigma} x d x-\frac{1}{2} Q^{2} h_{b}^{T P} \int_{Q}^{\mu+\frac{\sigma}{2}} \frac{1}{\sigma x} d x-w Q-c_{t} Q-t h_{b}^{T P} Q \\
& =\mu\left(p+\frac{1}{2} h_{b}^{T P}\right)+\frac{1}{\sigma} Q\left(p+s_{b}+h_{b}^{T P}\right) \int_{Q}^{\mu+\frac{\sigma}{2}} d x-\frac{1}{\sigma}\left(p+s_{b}+\frac{1}{2} h_{b}^{T P}\right) \int_{Q}^{\mu+\frac{\sigma}{2}} x d x \\
& -Q h_{b}^{T P}-\frac{1}{2 \sigma} Q^{2} h_{b}^{T P} \int_{Q}^{\mu+\frac{\sigma}{2}} \frac{1}{x} d x-w Q-c_{t} Q-t h_{b}^{T P} Q \\
& =\mu\left(p+\frac{1}{2} h_{b}^{T P}\right)-Q\left(w+c_{t}+h_{b}^{T P}+t h_{b}^{T P}\right)-\frac{1}{2 \sigma} Q^{2} h_{b}^{T P}\left\{\ln \left(\mu+\frac{\sigma}{2}\right)-\ln Q\right\} \\
& +\frac{1}{\sigma} Q\left(p+s_{b}+\frac{1}{2} h_{b}^{T P}+\frac{1}{2} h_{b}^{T P}\right)\left(\mu+\frac{\sigma}{2}-Q\right)-\frac{1}{2 \sigma}\left(p+s_{b}+\frac{1}{2} h_{b}^{T P}\right)\left\{\left(\mu+\frac{\sigma}{2}\right)^{2}-Q^{2}\right\} \\
& =\mu\left(p+\frac{1}{2} h_{b}^{T P}\right)-Q\left(w+c_{t}+h_{b}^{T P}+t h_{b}^{T P}\right)-\frac{1}{2 \sigma}\left(p+s_{b}+\frac{1}{2} h_{b}^{T P}\right)\left(Q-\mu-\frac{\sigma}{2}\right)^{2} \\
& -\frac{1}{2 \sigma} Q h_{b}^{T P}\left(Q-\mu-\frac{\sigma}{2}\right)-\frac{1}{2 \sigma} Q^{2} h_{b}^{T P}\left\{\ln \left(\mu+\frac{\sigma}{2}\right)-\ln Q\right\} \text { (A1) }
\end{aligned}
$$

Considering $d E\left(\pi_{b}^{T P}\right) / d Q=0$, from equation (A1), we have

$$
\begin{aligned}
& -\left(w+c_{t}+h_{b}^{T P}+t h_{b}^{T P}\right)-\frac{1}{\sigma}\left(p+s_{b}+\frac{1}{2} h_{b}^{T P}\right)\left(Q-\mu-\frac{\sigma}{2}\right)-\frac{1}{2 \sigma} Q h_{b}^{T P} \\
& -\frac{1}{2 \sigma} h_{b}^{T P}\left(Q-\mu-\frac{\sigma}{2}\right)-\frac{1}{\sigma} Q h_{b}^{T P}\left\{\ln \left(\mu+\frac{\sigma}{2}\right)-\ln Q\right\}+\frac{1}{2 \sigma} Q^{2} h_{b}^{T P} \frac{1}{Q}=0, \\
& -2 \sigma\left(w+c_{t}+h_{b}^{T P}+t h_{b}^{T P}\right)-2\left(p+s_{b}+\frac{1}{2} h_{b}^{T P}\right)\left(Q-\mu-\frac{\sigma}{2}\right) \\
& -h_{b}^{T P}\left(Q-\mu-\frac{\sigma}{2}\right)-2 Q h_{b}^{T P}\left\{\ln \left(\mu+\frac{\sigma}{2}\right)-\ln Q\right\}=0, \\
& 2 Q\left\{h_{b}^{T P} \ln Q-h_{b}^{T P} \ln \left(\mu+\frac{\sigma}{2}\right)-p-s_{b}-\frac{1}{2} h_{b}^{T P}-\frac{1}{2} h_{b}^{T P}\right\}+h_{b}^{T P}\left(\mu+\frac{\sigma}{2}\right) \\
& -2 \sigma\left(w+c_{t}+h_{b}^{T P}+t h_{b}^{T P}\right)+2\left(p+s_{b}+\frac{1}{2} h_{b}^{T P}\right)\left(\mu+\frac{\sigma}{2}\right)=0, \\
& Q\left\{h_{b}^{T P} \ln Q-h_{b}^{T P} \ln \left(\mu+\frac{\sigma}{2}\right)-p-s_{b}-h_{b}^{T P}\right\}-\sigma\left(w+c_{t}+h_{b}^{T P}+t h_{b}^{T P}\right) \\
& +\left(p+s_{b}+h_{b}^{T P}\right)\left(\mu+\frac{\sigma}{2}\right)=0
\end{aligned}
$$

We can calculate $d^{2} E\left(\pi_{b}^{T P}\right) / d Q^{2}$ from equation (A2) as given below:

$$
\begin{aligned}
\frac{d^{2} E\left(\pi_{b}^{T P}\right)}{d Q^{2}} & =h_{b}^{T P} \ln Q-h_{b}^{T P} \ln \left(\mu+\frac{\sigma}{2}\right)-p-s_{b}-h_{b}^{T P}+Q h_{b}^{T P} \frac{1}{Q} \\
& \left.=-\left\{p+s_{b}+h_{b}^{T P} \ln \left(\frac{\mu+\sigma / 2}{Q}\right)\right\}<0 \quad \text { (A3 }\right)
\end{aligned}
$$

So, $E\left(\pi_{b}^{T P}\right)$ is concave in $Q$ and hence, $Q$ calculated from the implicit equation (A2) is the optimal value of the order quantity to maximize $E\left(\pi_{b}^{T P}\right)$.

Equation (A2) shows that $Q$ is a function of $w$. So, taking derivative with respect to $w$ in equation (A2), we get

$$
\begin{gathered}
\frac{d Q}{d w}\left\{h_{b}^{T P} \ln Q-h_{b}^{T P} \ln \left(\mu+\frac{\sigma}{2}\right)-p-s_{b}-h_{b}^{T P}\right\}+Q\left\{h_{b}^{T P} \frac{1}{Q} \frac{d Q}{d w}\right\}-\sigma=0 \\
\frac{d Q}{d w}=\frac{\sigma}{h_{b}^{T P}\left\{\ln Q-\ln \left(\mu+\frac{\sigma}{2}\right)\right\}-p-s_{b}}<0 \quad \text { (A4) }
\end{gathered}
$$

The vendor's expected profit is

$$
E\left(\pi_{v}^{T P}\right)=(w-c) Q-\frac{Q^{2}}{2 p_{v}} h_{v}^{T P}
$$

From equation (A5), $d E\left(\pi_{v}^{T P}\right) / d w=0$ gives,

$$
(w-c) \frac{d Q}{d w}+Q-\frac{Q}{p_{v}} h_{v}^{T P} \frac{d Q}{d w}=0 w=c+\frac{Q}{p_{v}} h_{v}^{T P}-\frac{Q}{d Q / d w},
$$

[using equation (A4)]

$$
w=c+\frac{Q}{p_{v}} h_{v}^{T P}-\frac{Q\left[h_{b}^{T P}\left\{\ln Q-\ln \left(\mu+\frac{\sigma}{2}\right)\right\}-p-s_{b}\right]}{\sigma}
$$

This $w$ is the optimal wholesale price, because $E$ ( $\pi_{v}^{T P}$ ) is concave in $w$, shown below.

$$
\frac{d^{2} E\left(\pi_{v}^{T P}\right)}{d w^{2}}=\frac{d Q}{d w}\left[\frac{h_{v}^{T P}}{p_{v}}+\frac{h_{b}^{T P} \ln \left(\frac{\mu+\sigma / 2}{Q}\right)+\left(p-h_{b}^{T P}\right)+s_{b}}{\sigma}\right]-1<0
$$


Putting the value of $w$ in equation (A2), we have

$$
\begin{aligned}
& Q h_{b}^{T P} \ln Q-Q\left\{h_{b}^{T P} \ln \left(\mu+\frac{\sigma}{2}\right)+p+s_{b}+h_{b}^{T P}\right\}+\left(p+s_{b}+h_{b}^{T P}\right)\left(\mu+\frac{\sigma}{2}\right) \\
& -\sigma\left(c_{t}+h_{b}^{T P}+t h_{b}^{T P}\right)-\sigma\left[c+\frac{Q}{p_{v}} h_{v}^{T P}-\frac{Q}{\sigma}\left\{h_{b}^{T P}\left(\ln Q-\ln \left(\mu+\frac{\sigma}{2}\right)\right)-p-s_{b}\right\}\right]=0, \\
& 2 Q h_{b}^{T P} \ln Q-Q\left\{2 h_{b}^{T P} \ln \left(\mu+\frac{\sigma}{2}\right)+h_{b}^{T P}+\frac{\sigma}{p_{v}} h_{v}^{T P}+2 p+2 s_{b}\right\} \\
& +\left(p+s_{b}+h_{b}^{T P}\right)\left(\mu+\frac{\sigma}{2}\right)-\sigma\left(c+c_{t}+h_{b}^{T P}+t h_{b}^{T P}\right)=0
\end{aligned}
$$

Implicit equation (A8) gives the optimal value of the order quantity, $Q$ to maximize $E\left(\pi_{b}^{T P}\right)$.

\section{REFERENCES}

1. Sjoerdsma M (1991). Consignment: present and future. Hosp. Ma. Man. Quarterly 13(1):6-9.

2. Harrington L (1996). Consignment selling: trend or another wild idea? Transportation and Distribution 37(6): 45-48.

3. Wang Y, Jiang L and Shen ZJ (2004). Channel performance under consignment contract with revenue sharing. Management Science 50(1): 3447.

4. Williams MK (2000). Making consignment and vendor-managed inventory work for you. Hospital Material Management Quarterly 21(4): 59-63.

5. Valentini G and Zavanella L (2003). The consignment stock of inventories: industrial case and performance analysis. International Journal of Production Economics 81-82: 215-224.

6. Chen SL and Liu CL (2008). The optimal consignment policy for the manufacturer under supply chain co-ordination. International Journal of Production Research 46(18): 51215143.

7. Goyal SK (1977). An integrated inventory model for a single-supplier single-customer problem.International Journal of Production Research 5(1): 107-111.

8. Voros J (1999). On the risk-based aggregate planning for seasonal products. International Journal of Production Economics 59: 195-201.

9. Panda S, Senapati S and Basu M (2008). Optimal replenishment policy for perishable seasonal products in a season with ramp-type time dependent demand. Computers \& Industrial Engineering 54: 301-314.
10. Wanke PF (2008). The uniform distribution as a first practical approach to new product inventory management. Int. J. Production Economics 114: 811-819.

11. Kulp SC (2002). The effect of information precision and information reliability on manufacturer-retailer relationships. The Accounting Review 77(3): 653-677.

12. Zhou YW and Wang SD (2007). Optimal production and shipment models for a singlevendor-single-buyer integrated system. European Journal of Operational Research 180: 309-328.

13. Zavanella L and Zanoni S (2009). A one-vendor multi-buyer integrated production-inventory model: The 'consignment stock' case. International Journal of Production Economics 118(1): 225-232.

14. Hoque MA (2013). A vendor-buyer integrated production-inventory model with normal distribution of lead time. Int. J. Production Economics 144: 409-417.

15. Sajadieh MS, Jokar MRA and Modarres M (2009). Developing a coordinated vendor-buyer model in two-stage supply chains with stochastic lead-times. Computers \& Operations Research 36: $2484-2489$.

16. Yu-Jen Lin (2009). An integrated vendor-buyer inventory model with backorder price discount and effective investment to reduce ordering cost. Computers \& Industrial Engineering 56: 15971606.

17. Islam SMS (2014). Single-vendor single-buyer optimal consignment policy for a seasonal product. HSTU Journal of Science and Technology 12: (In press).

18. Gallego G and Ryzin VG (1994). Optimal dynamic pricing of inventories with stochastic demand over finite horizons. Management Science 40(8): 999-1020.

19. Emmons H and Gilbert SM (1998). Note: the role of returns policies in pricing and inventory decisions for catalogue goods. Management Science 44(2): 276-283.

20. Petruzzi NC and Dada M (1999). Pricing and the newsvendor problem: a review with extensions. Operations Research 47(2): 183-194. 